\title{
Triband Omnidirectional Circularly Polarized Dielectric Resonator Antenna with Top-Loaded Alford Loop
}

\author{
Chunxia Cheng, Fushun Zhang, Yali Yao, and Fan Zhang \\ National Laboratory of Science and Technology on Antennas and Microwaves, Xidian University, Xi'an 710071, China \\ Correspondence should be addressed to Chunxia Cheng; cheng_chunxia@126.com
}

Received 22 May 2014; Revised 12 August 2014; Accepted 1 September 2014

Academic Editor: Byungje Lee

Copyright (C) 2014 Chunxia Cheng et al. This is an open access article distributed under the Creative Commons Attribution License, which permits unrestricted use, distribution, and reproduction in any medium, provided the original work is properly cited.

\begin{abstract}
A triband omnidirectional circularly polarized dielectric resonator antenna with a top-loaded modified Alford loop for GSM, WLAN, and WiMAX applications is proposed. Fed by an axial probe, the DRA (dielectric resonator antenna) radiates like a vertically polarized electric monopole. The top-loaded modified Alford loop provides an equivalent horizontally polarized magnetic dipole mode at triband. Omnidirectional CP (circular polarized) fields can be obtained when the two orthogonally polarized fields are equal in amplitude with phase quadrature. The antenna has been successfully simulated, fabricated, and measured. The experimental and numerical results exhibit that the antenna can obtain usable CP bandwidths of $1.925-1.955 \mathrm{GHz}, 2.36-2.48 \mathrm{GHz}$, and 3.502-3.53 GHz with return loss larger than $10 \mathrm{~dB}$ and axial ratio less than $3 \mathrm{~dB}$. In addition, over the three bands, the antenna obtains very good omnidirectional CP radiation patterns in the azimuth plane. Moreover, an average CP gain in the azimuth plane of $1.2,1.6$, and $-1.5 \mathrm{dBic}$ for the lower, middle, and upper bands has been obtained.
\end{abstract}

\section{Introduction}

In modern wireless communication systems, the demand for antennas with multiband operations has increased since such antennas are vital for combining multiple different communication standards in a single compact wireless system. Also, circularly polarized antennas are widely used in modern wireless systems to suppress multipath interferences. Moreover, omnidirectional antennas are very attractive for applications in wireless communications because they can provide full coverage of signal to maintain good communication links at all angles. Thus, multiband omnidirectional circular polarized antennas are ideal for modern wireless communications. Several types of triband antennas have been reported, such as a CPW-fed monopole antenna with a parasitic circular patch and a pair of symmetrical inverted$L$ strips in [1], a monopole antenna with complementary split-ring resonators in [2], a single-loop resonator in [3], and a rectangle-loaded monopole antenna with inverted$L$ slot in [4]. However, those designs can only provide triband linear-polarized omnidirectional patterns. As the growing interest in multiband $\mathrm{CP}$ antennas, various designs of multiband circularly polarized antennas have also been proposed, including the dual-band CPW-fed circularly polarized antenna with two orthogonal slots [5], a dual-band CP antenna with two square slots in the opposite corner of the ground plane and two truncated corners of the main slot [6], and a dual-band circularly polarized antenna with slots loaded in the two opposite corners and the halberd-shaped strip connected at the end of the signal line [7]. Unfortunately, although the above designs achieve multiband CP radiations, they all cannot achieve omnidirectional patterns. In addition, several types of omnidirectional CP antennas with singleband $[8,9]$ or dual-band [10] have been found in recent literatures. However, those designs can only provide one or dual operation band.

In this paper, a triband omnidirectional $\mathrm{CP}$ cylindrical dielectric resonator antenna (DRA) with a top-loaded modified Alford loop which satisfies 1.9 GHz GSM, 2.4 GHz WLAN, and $3.5 \mathrm{GHz}$ WiMAX applications is proposed. The DRA radiates like an electric monopole and the top-loaded modified Alford loop radiates as an equivalent magnetic dipole. By properly selecting shapes and dimensions of the DRA and the Alford loop, the orthogonal electric fields of the 


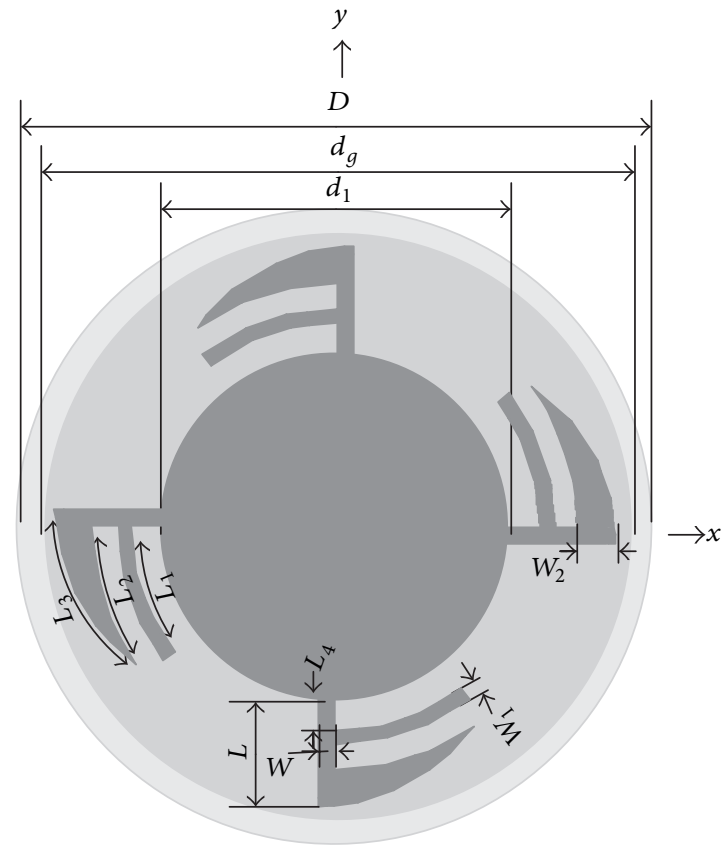

(a)

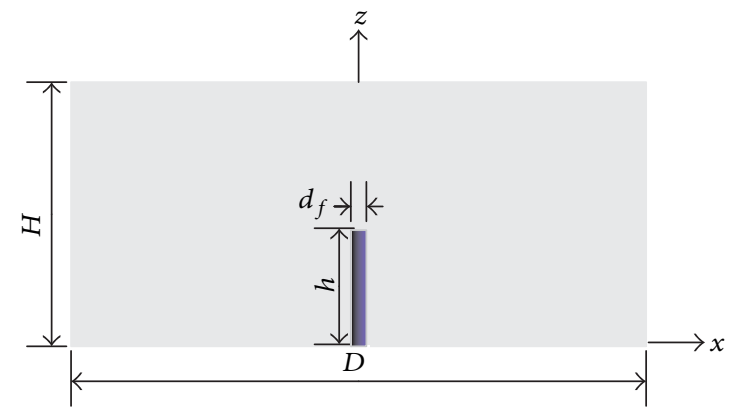

(b)

Figure 1: Configuration of the proposed antenna. (a) Top view. (b) Side view.

TABLE 1: Dimensions of the proposed antenna (unit: $\mathrm{mm}$ ).

\begin{tabular}{cccccccccccccc}
\hline$D$ & $H$ & $d_{g}$ & $h$ & $d_{f}$ & $d_{1}$ & $L$ & $L_{1}$ & $L_{2}$ & $L_{3}$ & $L_{4}$ & $W$ & $W_{1}$ & $W_{2}$ \\
\hline 50 & 22.5 & 47 & 10 & 1.27 & 29.7 & 7.4 & 10.8 & 11.8 & 14.6 & 1.4 & 1.3 & 1.2 & 3.1 \\
\hline
\end{tabular}

equivalent electric and magnetic dipoles which are equal in amplitude with phase quadrature within the three separate frequency bands can be achieved. Details of the antenna design and experimental results are presented and discussed.

\section{Antenna Design}

The antenna design presented here is based on the omnidirectional circularly polarized dielectric resonator antenna with top-loaded Alford loop in [9]. In the present work, by modifying the top-loaded Alford loop the two orthogonally polarized fields are equal in amplitude with phase quadrature in three bands. The configuration of the proposed triband omnidirectional CP cylindrical DRA is shown in Figure 1. The DRA is designed to resonate in the middle band (about $2.4 \mathrm{GHz}$ ) with a diameter of $D=50 \mathrm{~mm}$, a height of $H=$ $22.5 \mathrm{~mm}$, and a dielectric constant of $\varepsilon_{r}=9.8$. The resonant frequency of the DRA in $\mathrm{TM}_{01 \delta}$-mode can be estimated using [11]:

$$
\begin{aligned}
f= & \frac{2.933 c \varepsilon_{r}^{-0.468}}{\pi D}\left\{1-\left[0.075-0.05\left(\frac{D}{4 H}\right)\right]\left[\frac{\varepsilon_{r}-10}{28}\right]\right\} \\
& \cdot\left\{1.048+0.377\left(\frac{D}{4 H}\right)-0.071\left(\frac{D}{4 H}\right)^{2}\right\} .
\end{aligned}
$$

The proposed DRA can be matched easily by simply adjusting the length $h$ of the probe. It is found that a good match can be obtained when $h=10 \mathrm{~mm}$. As shown in Figure 1(a), the circular patch of the modified Alford loop that locates on the top of the DRA has a diameter of $d_{1}$. Four conducting curved branches with the same width are extended from the patch and oriented in the counterclockwise direction. Four conducting curved branches with gradually narrow width are extended from the outer of the four inner branches. By adjusting the sizes of the modified Alford loop and ground plane $\left(d_{g}\right)$, the radiation fields of the electric and magnetic monopoles can be made equal in amplitude with phase quadrature, which are required for generating CP fields. The detailed dimensions of the proposed circularly polarized antenna are listed in Table 1. The lengths of the branches are approximately determined by

$$
\begin{gathered}
\frac{d_{1} \pi}{4}+L-\frac{W_{2}}{2}+\frac{L_{2}+L_{3}}{2}+L_{1}=\lambda_{l}, \\
\frac{d_{1} \pi}{4}+L-\frac{W_{2}}{2}+\frac{L_{2}+L_{3}}{2}=\lambda_{m}, \\
\frac{d_{1} \pi}{4}+L_{1}+\frac{W_{1}}{2}+L_{4}=\lambda_{u},
\end{gathered}
$$

where $d_{1} \pi / 4$ is a quarter of the circular patch circumference, $L_{1}$ is the length of the inner branch, $\left(L_{2}+L_{3}\right) / 2$ is the average length of the outer branch, $W_{1} / 2+L_{4}$ is the distance between 


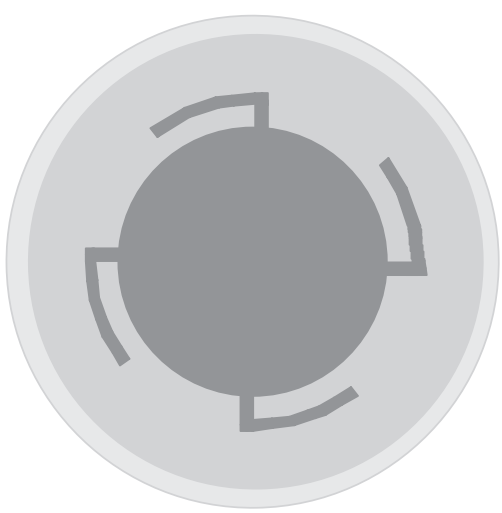

(a)

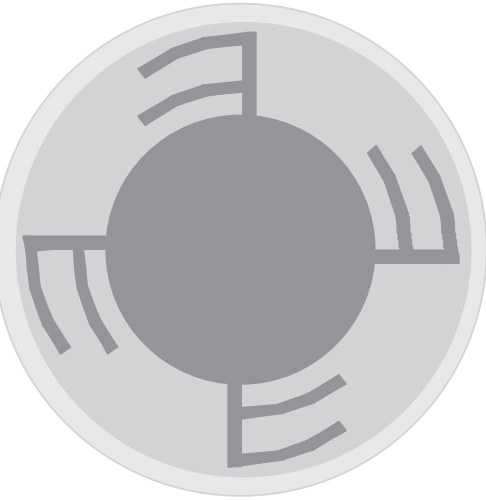

(b)

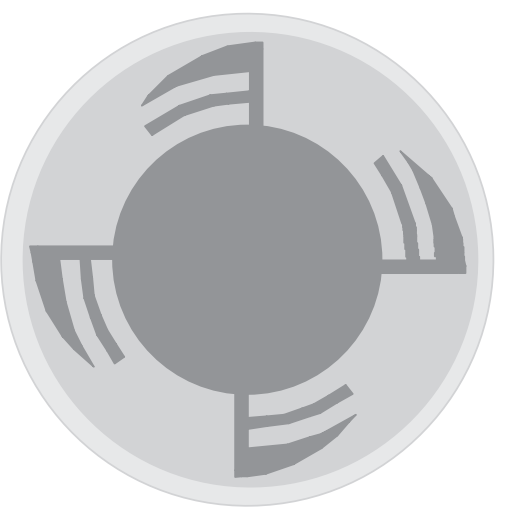

(c)

Figure 2: Three prototypes of the antenna. (a) Ant. I, (b) Ant. II, and (c) Ant. III.

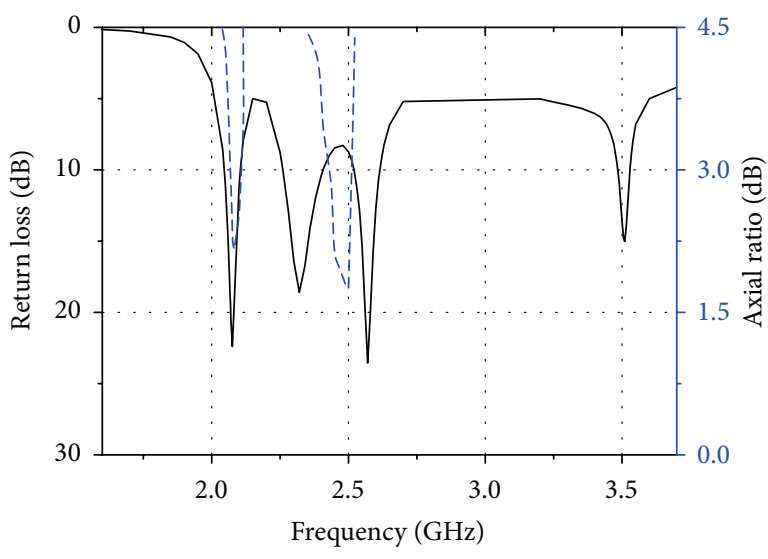

— Return loss of Antenna 1 - - - Axial ratio of Antenna 1

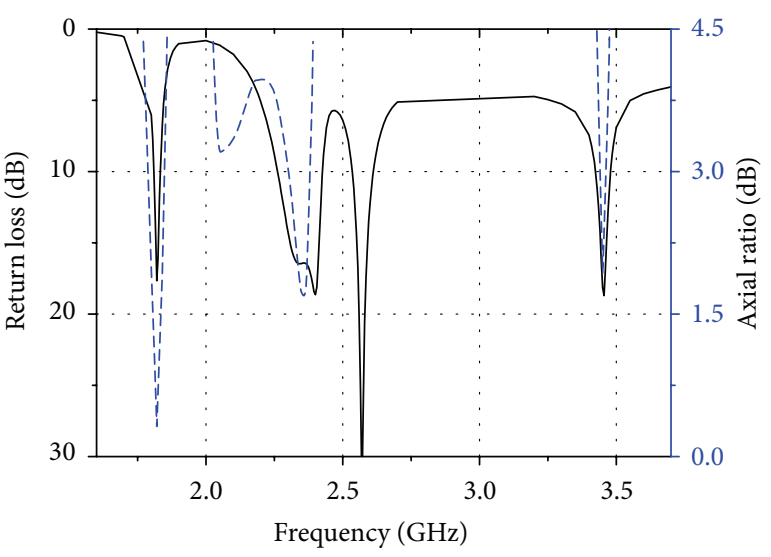

- Return loss of Antenna 2 - - - Axial ratio of Antenna 2

(a)

(b)

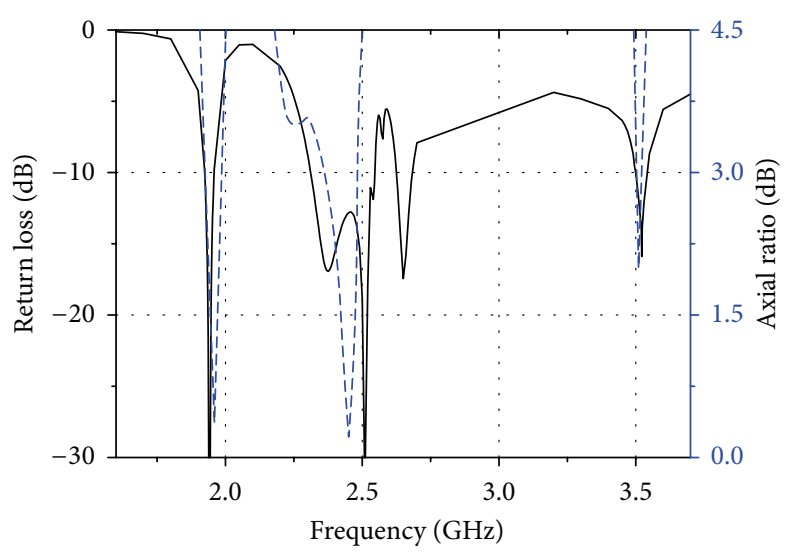

Return loss of Antenna 3

- - - Axial ratio of Antenna 3

(c)

FIGURE 3: Simulated return loss and axial ratio (theta $=90 \mathrm{deg}$ and $\mathrm{phi}=0 \mathrm{deg}$ ) of various antennas involved. (a) Ant. I, (b) Ant. II, and (c) Ant. III. 


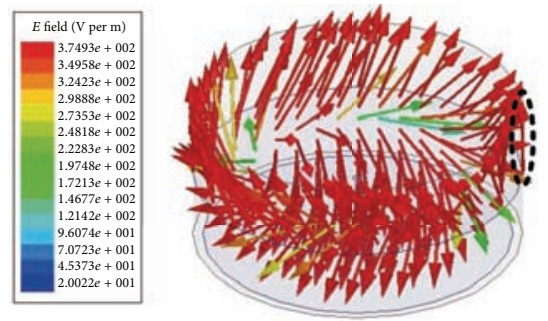

$1.937 \mathrm{GHz}$
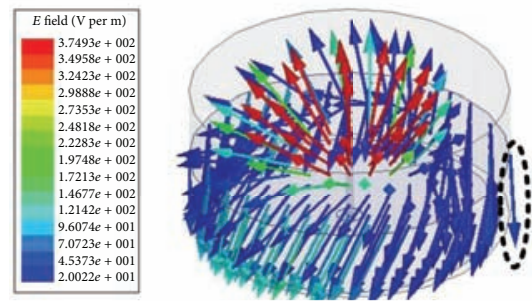

$1.937 \mathrm{GHz}$

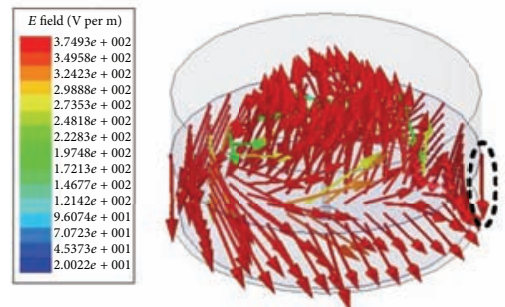

$1.937 \mathrm{GHz}$
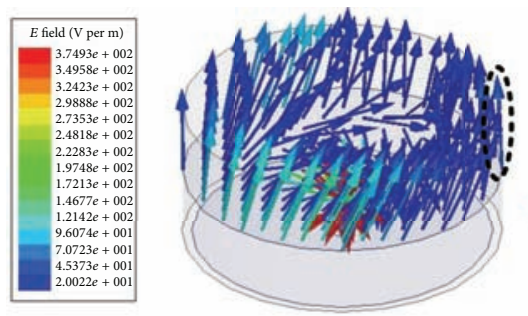

$1.937 \mathrm{GHz}$

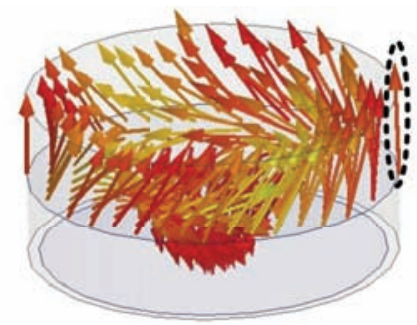

$2.45 \mathrm{GHz}$

(a)

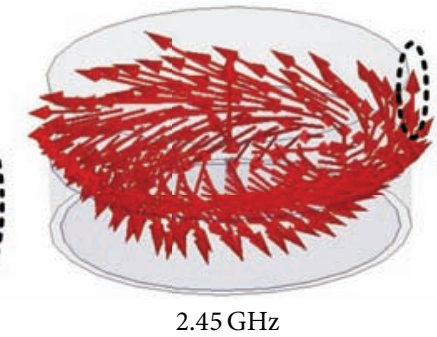

(b)

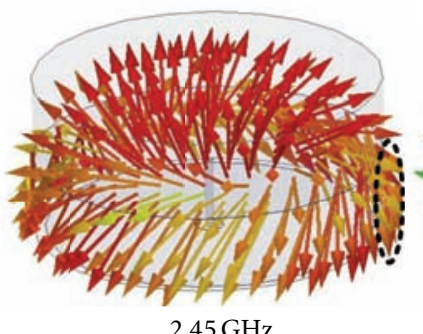

(c)

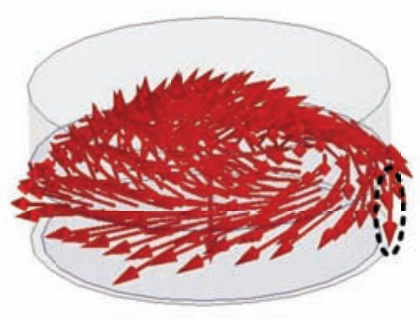

$2.45 \mathrm{GHz}$

(d)
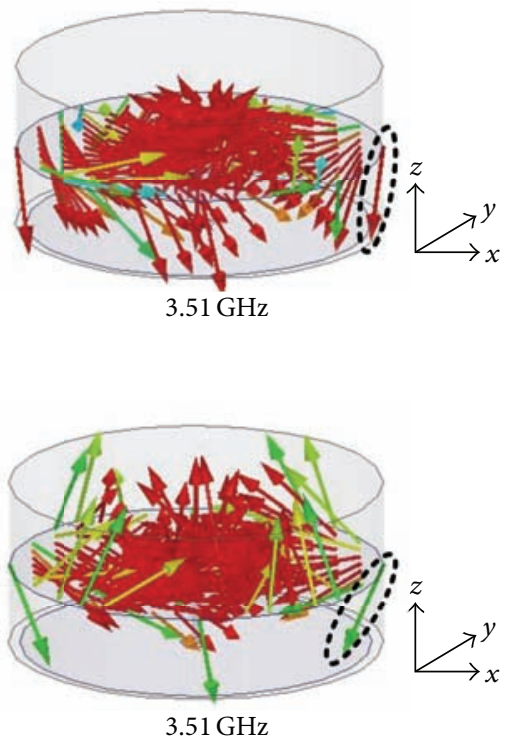

$3.51 \mathrm{GHz}$

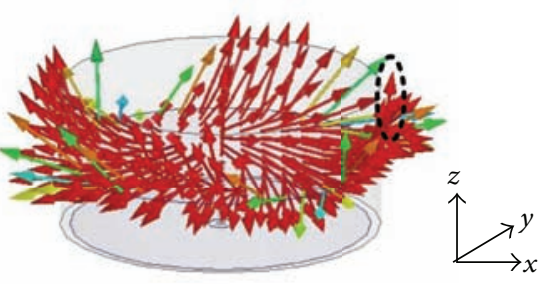

$3.51 \mathrm{GHz}$

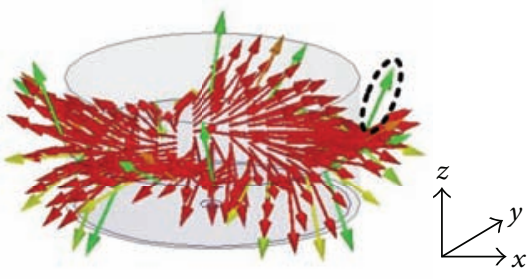

$3.51 \mathrm{GHz}$

FIGURE 4: Simulated $E$ fields inside the DRA at the three resonant frequencies with four phase angles: (a) $0^{\circ}$, (b) $90^{\circ}$, (c) $180^{\circ}$, and (d) $270^{\circ}$.

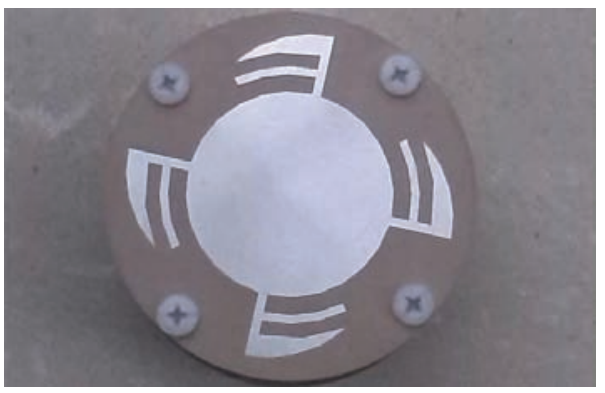

FIGURE 5: Photograph of the proposed antenna. 


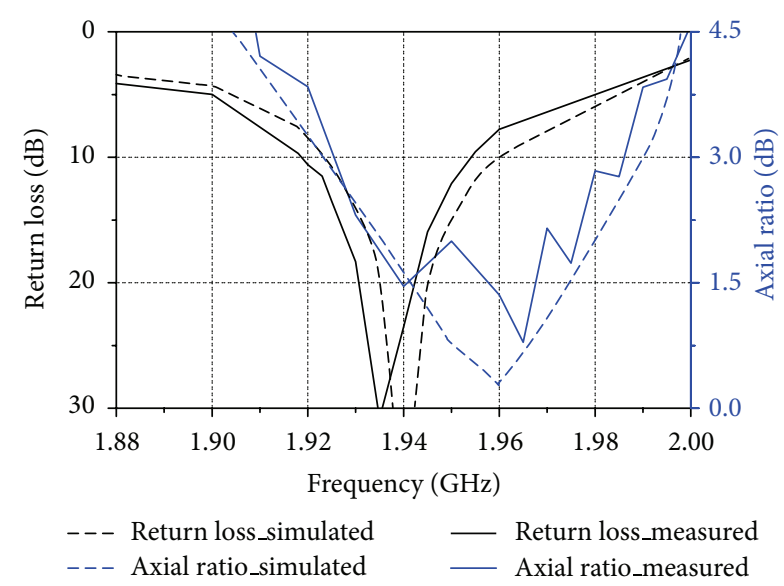

(a)

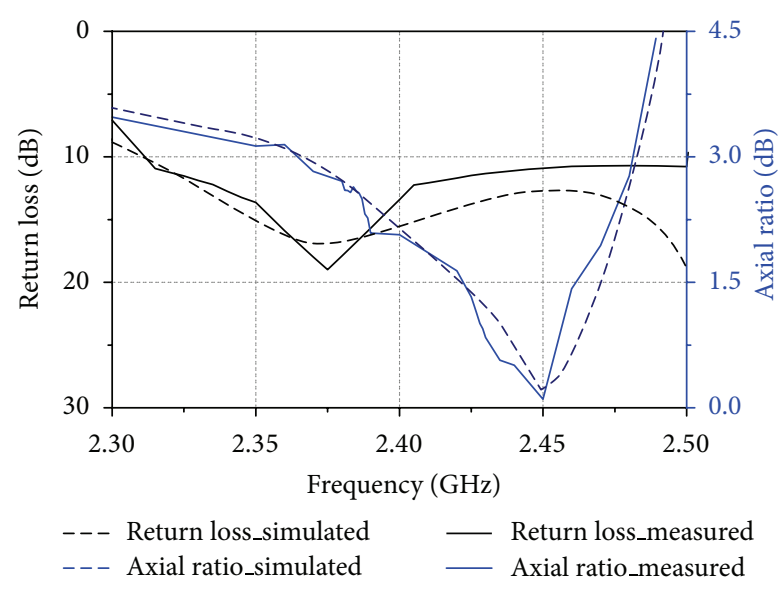

(b)

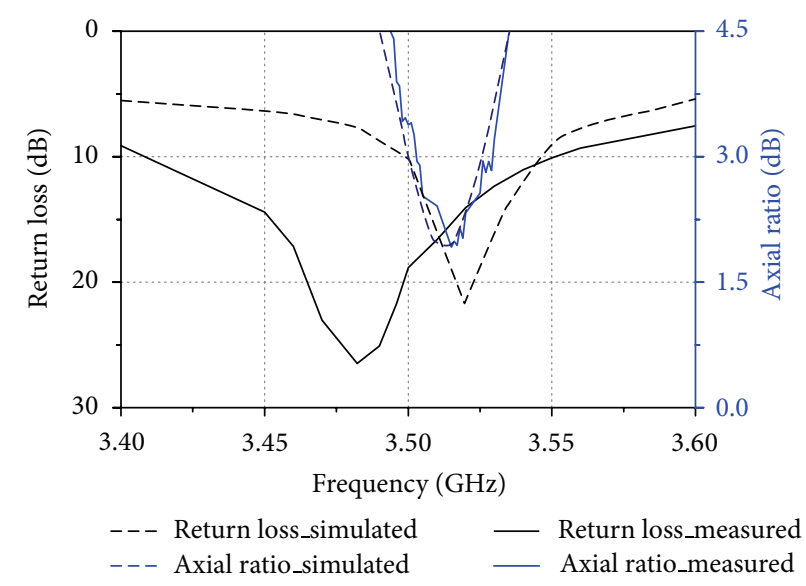

(c)

FIgURE 6: Simulated and measured return loss and AR of the proposed antenna. (a) Lower band, (b) middle band, and (c) upper band.

the inner branch and the circular patch, and $L-W_{2} / 2$ is the distance between the outer branch and the circular patch. $\lambda_{l}$, $\lambda_{m}$, and $\lambda_{u}$ are the lower, middle, and upper wave length, respectively. They are given by

$$
\begin{aligned}
& \lambda_{l}=\frac{C}{f_{l} \sqrt{\varepsilon_{\mathrm{eff}}}}, \\
& \lambda_{m}=\frac{C}{f_{m} \sqrt{\varepsilon_{\mathrm{eff}}}}, \\
& \lambda_{u}=\frac{C}{f_{u} \sqrt{\varepsilon_{\mathrm{eff}}}},
\end{aligned}
$$

where $f_{l}, f_{m}$, and $f_{u}$ are the lower, middle, and upper resonant frequency and $\varepsilon_{\text {eff }}$ is the relative effective permittivity.

For clarifying the improvement process, three prototypes of the antenna are defined as follows (Figure 2): Ant. I is the original antenna with four conducting curved branches of the same width extended from the top-loaded patch; Ant. II has four conducting curved branches with the same width which are extended from the outer of Ant. I; Ant. III is the final construction with the gradually narrow outer branches modified from those of Ant. II. These three prototypes are simulated by a high frequency structure simulator (HFSS 13.0) and the detailed performances are presented in Figure 3: Ant. I has one usable circularly polarized band (overlap bands of return loss $>10 \mathrm{~dB}$ and $\mathrm{AR}<3 \mathrm{~dB}$ ), while Ant. II and Ant. III have three. Furthermore, the useable bandwidths of Ant. III are broader, especially the middle band. It is observed that the gradually narrow outer branches have positive influence on circular polarized fields of the antenna.

The resonant $E$ fields of xoy-plane inside the DRA for the lower $(1.937 \mathrm{GHz})$, middle $(2.45 \mathrm{GHz})$, and upper $(3.51 \mathrm{GHz})$ frequencies of $0 \mathrm{deg}, 90 \mathrm{deg}, 180 \mathrm{deg}$, and $270 \mathrm{deg}$ are simulated using HFSS. The simulated fields are shown in Figure 4. In the three frequencies, the wave propagation direction is along the outer normal direction of the DRA. In order to determine the wave polarization, we observed electric field vector direction (inside the black dotted line) variety with phase angles. In the lower frequency, the observed $E$ field flows from the $+z$-axis and $-y$-axis to $-z$-axis, and the wave propagation direction is $+x$-axis, generating a RHCP radiation. In the middle frequency, the observed $E$ field flows from the $+z$-axis and $+y$-axis to $-z$-axis, resulting in a LHCP. And in the upper frequency, the observed $E$ field flows from the $-z$-axis and $-y$-axis to $+z$-axis, also producing a LHCP. 

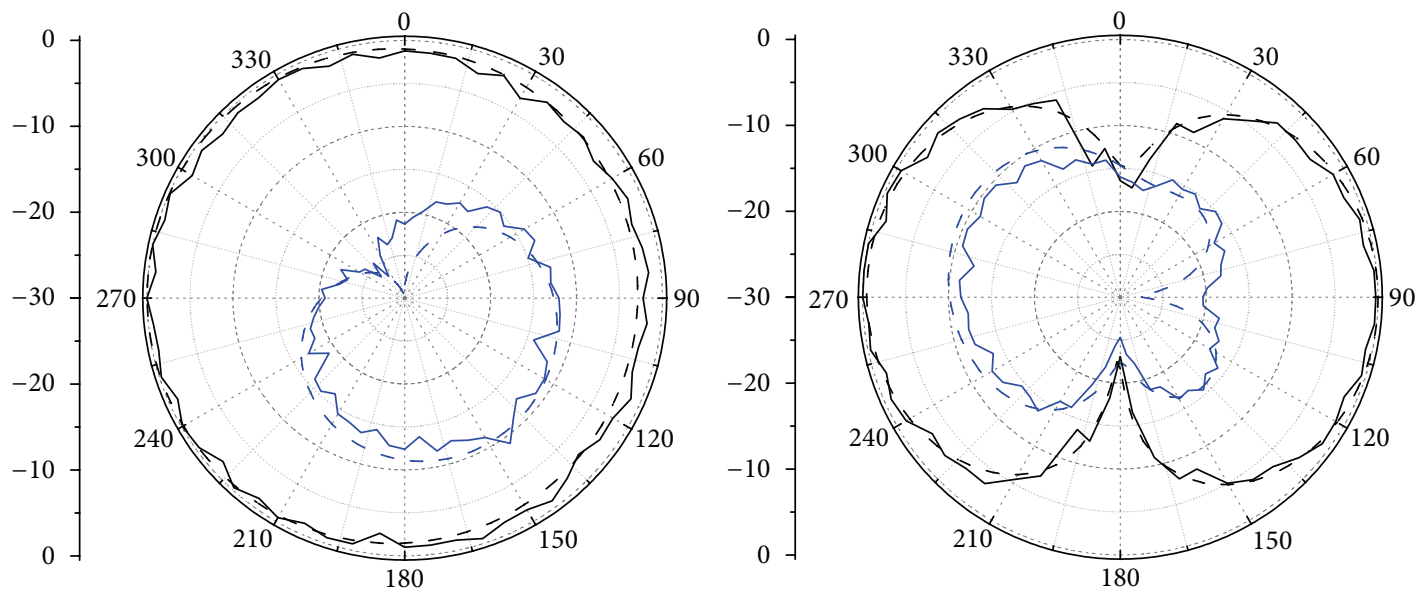

(a)
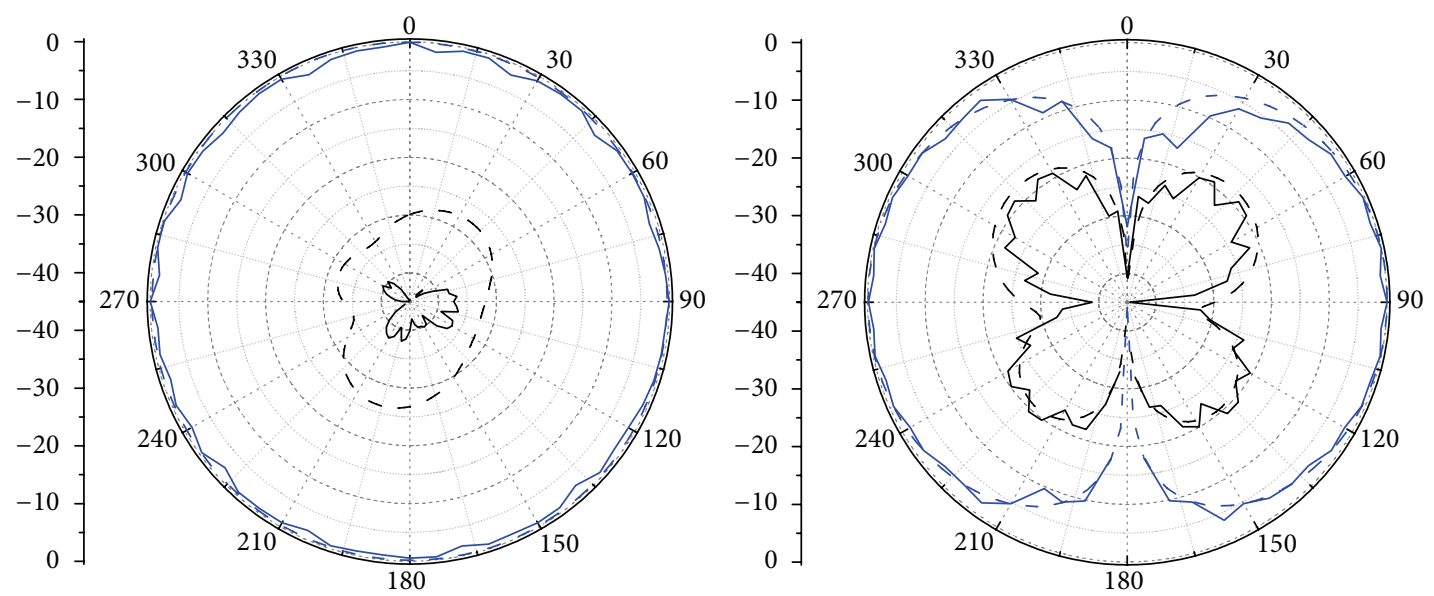

(b)
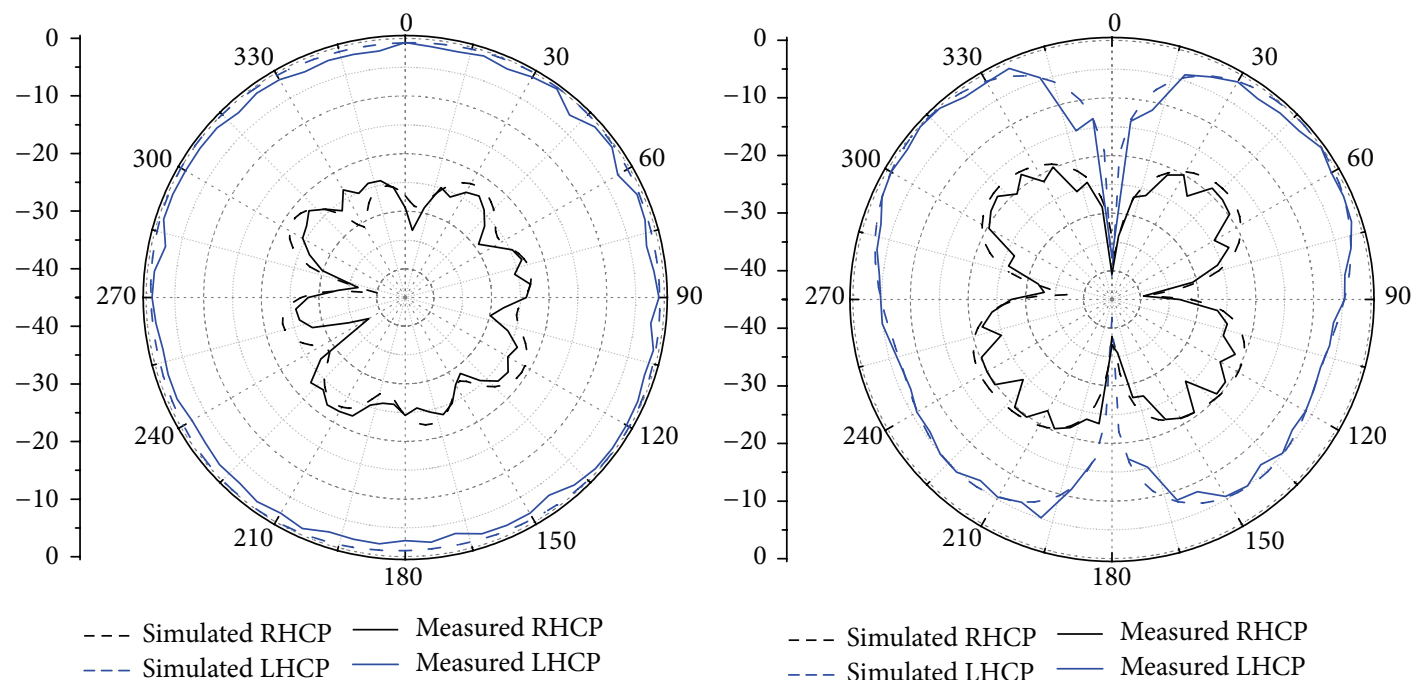

(c)

FIGURE 7: Simulated and measured radiation patterns in the azimuth plane (left) and the elevation plane (right). (a) $1.937 \mathrm{GHz}$. (b) $2.45 \mathrm{GHz}$. (c) $3.51 \mathrm{GHz}$. 


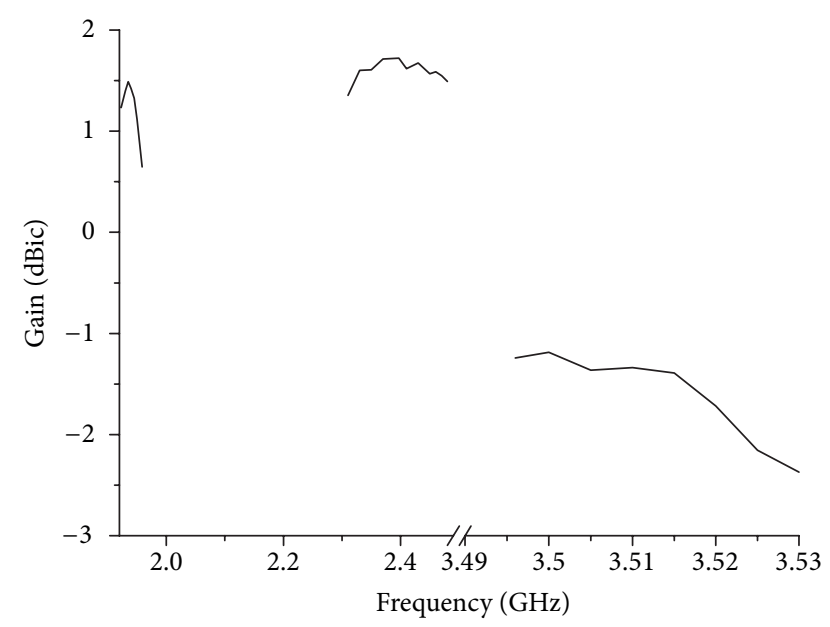

Figure 8: Measured CP gains against frequency for the proposed antenna.

\section{Experimental Results and Discussion}

According to the dimensions shown in Figure 1, a fabricated prototype for the proposed antenna has been constructed and measured. The photograph of the prototype is exhibited in Figure 5. The simulated and measured return loss and axial ratio (theta $=90 \mathrm{deg}$ and $\mathrm{phi}=0 \mathrm{deg}$ ) versus frequency are shown in Figure 6. The measured $10 \mathrm{~dB}$ impedance bandwidths are $35 \mathrm{MHz}(1.92-1.955 \mathrm{GHz}), 185 \mathrm{MHz}(2.315-$ $2.50 \mathrm{GHz})$, and $135 \mathrm{MHz}(3.415-3.55 \mathrm{GHz})$, respectively, and the $3 \mathrm{~dB}$ axial ratio bandwidths are approximately $70 \mathrm{MHz}$ $(1.925-1.985 \mathrm{GHz}), 120 \mathrm{MHz}(2.36-2.48 \mathrm{GHz})$, and $28 \mathrm{MHz}$ $(3.502-3.53 \mathrm{GHz})$. It is observed that the usable bandwidths are $30 \mathrm{MHz}(1.925-1.955 \mathrm{GHz}), 120 \mathrm{MHz}(2.36-2.48 \mathrm{GHz})$, and $28 \mathrm{MHz}(3.502-3.53 \mathrm{GHz})$. There has been a good agreement between the simulated and measured results.

The RHCP and LHCP radiation patterns are measured in the azimuth ( $x-y$ plane) and elevation ( $x-z$ plane $)$ planes at the frequency of 1.937, 2.45, and $3.51 \mathrm{GHz}$ in Figure 7. It is seen that the proposed antenna exhibits a good omnidirectional $\mathrm{CP}$ pattern in the azimuth plane and a bidirectional pattern in the elevation plane.

The measured CP gains in the xoy-plane of the proposed antenna are shown in Figure 8. From the right figure of Figure 7, it can be seen that the maximum CP gain for the upper band is not in the xoy-plane, but the maximum CP gains for the lower and middle bands are in the xoy-plane. The ground plane is larger relative to the upper frequency wavelength; thus the maximum CP gain is above xoy-plane. So, the CP gain for upper bands is low. The average gains of $1.2,1.6$, and $-1.5 \mathrm{dBic}$ for the lower, middle, and upper bands, respectively, are obtained.

\section{Conclusion}

In this paper, a triband omnidirectional CP DRA with a toploaded modified Alford loop is proposed. The DRA fed by an axial probe at the center of its bottom. The technique of combining equivalent electric and magnetic monopoles is adopted in the design; the former and the latter are obtained through the DRA and the modified Alford loop, respectively. By tuning the dimensions of the Alford loop, the radiation fields of the equivalent electric and magnetic monopoles can be made equal in amplitude but different in phase by $90^{\circ}$ at three resonant frequency bands, thus generating triband omnidirectional CP fields. The usable bandwidths of the antenna are $1.5 \%, 5.0 \%$, and $1.0 \%$. In addition, the antenna shows good omnidirectional $\mathrm{CP}$ radiation patterns in the azimuth plane over the three bands. And the average $\mathrm{CP}$ gains in $x o y$-plane are $1.2,1.6$, and $-1.5 \mathrm{dBic}$ for the lower, middle, and upper bands, respectively.

\section{Conflict of Interests}

The authors declare that there is no conflict of interests regarding the publication of this paper.

\section{References}

[1] L. Dong, Z. Zhang, W. Li, and G. Fu, "A compact CPWFED monopole antenna with triple bands for WLAN/WiMAX applications," Progress in Electromagnetics Research Letters, vol. 39, pp. 103-113, 2013.

[2] S. C. Basaran, U. Olgun, and K. Sertel, "Multiband monopole antenna with complementary split-ring resonators for WLAN and WiMAX applications," Electronics Letters, vol. 49, no. 10, pp. 636-638, 2013.

[3] R. Wen, "Compact planar triple-band monopole antennas based on a single-loop resonator," Electronics Letters, vol. 49, no. 15, pp. 916-918, 2013.

[4] H. Chen, X. Yang, Y.-Z. Yin, J.-J. Wu, and Y.-M. Cai, “Tri-band rectangle-loaded monopole antenna with inverted-L slot for WLAN/WiMAX applications," Electronics Letters, vol. 49, pp. 1261-1262, 2013.

[5] M.-Z. Wang, F.-S. Zhang, Y. Zhu, and L.-T. Ma, "Design of CPW-fed circularly polarized antenna with two orthogonal slots," Progress in Electromagnetics Research Letters, vol. 33, pp. 109-117, 2012.

[6] F.-X. Wu, W.-M. Li, and S.-M. Zhang, "Dual-band CPW-fed circularly-polarized slot antenna for DMB/WiMAX application," Progress in Electromagnetics Research Letters, vol. 30, pp. 185-193, 2012.

[7] X.-Q. Zhang, Y.-C. Jiao, and W.-H. Wang, "Compact dual-band dual-sense circularly-polarized CPW-fed slot antenna," Progress in Electromagnetics Research Letters, vol. 34, pp. 197-205, 2012.

[8] A. Narbudowicz, X. L. Bao, and M. J. Ammann, "Omnidirectional circularly-polarised microstrip patch antenna," Electronics Letters, vol. 48, no. 11, pp. 614-615, 2012.

[9] W. W. Li and K. W. Leung, "Omnidirectional circularly polarized dielectric resonator antenna with top-loaded alford loop for pattern diversity design," IEEE Transactions on Antennas and Propagation, vol. 61, no. 8, pp. 4246-4256, 2013.

[10] B.-C. Park and J.-H. Lee, "Dual-band omnidirectional circularly polarized antenna using zeroth- and first-order modes," IEEE Antennas and Wireless Propagation Letters, vol. 11, pp. 407-410, 2012.

[11] A. Petosa, Dielectric Resonator Antenna Handbook, Artech House, Norwood, Mass, USA, 2007. 

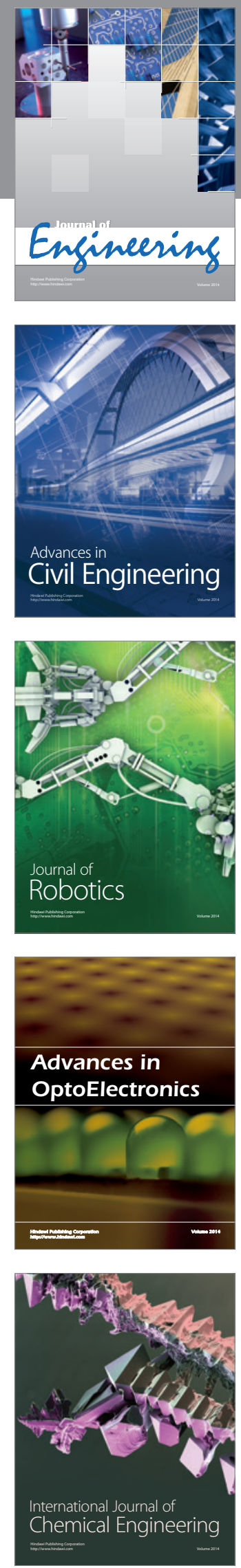

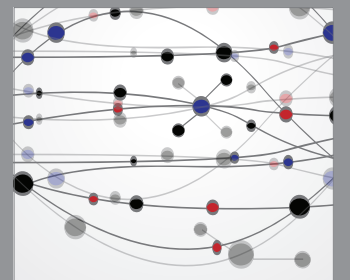

The Scientific World Journal
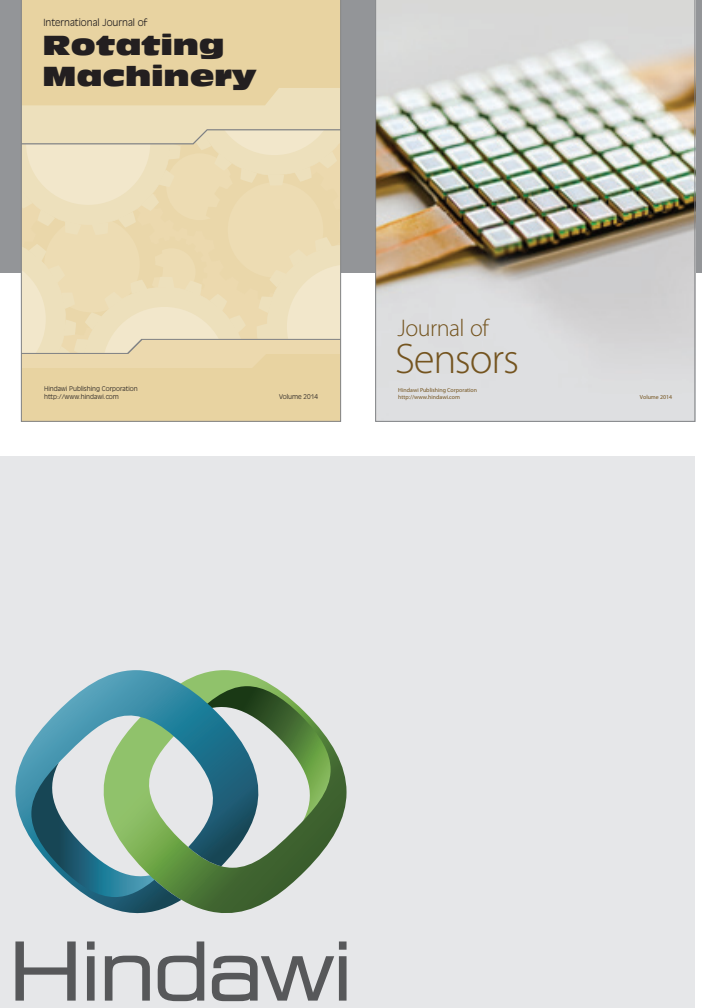

Submit your manuscripts at http://www.hindawi.com
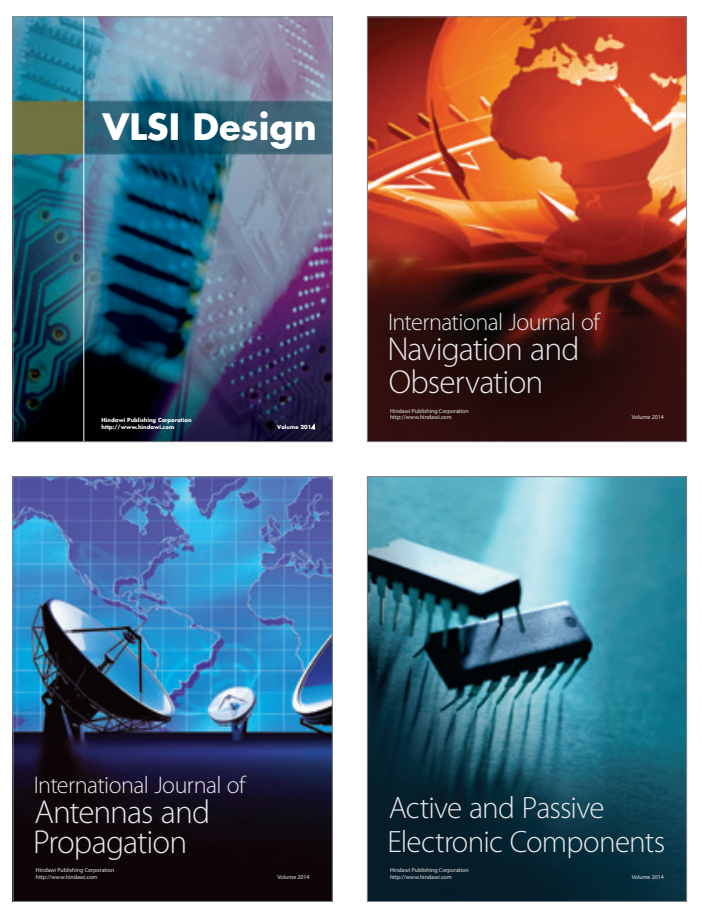
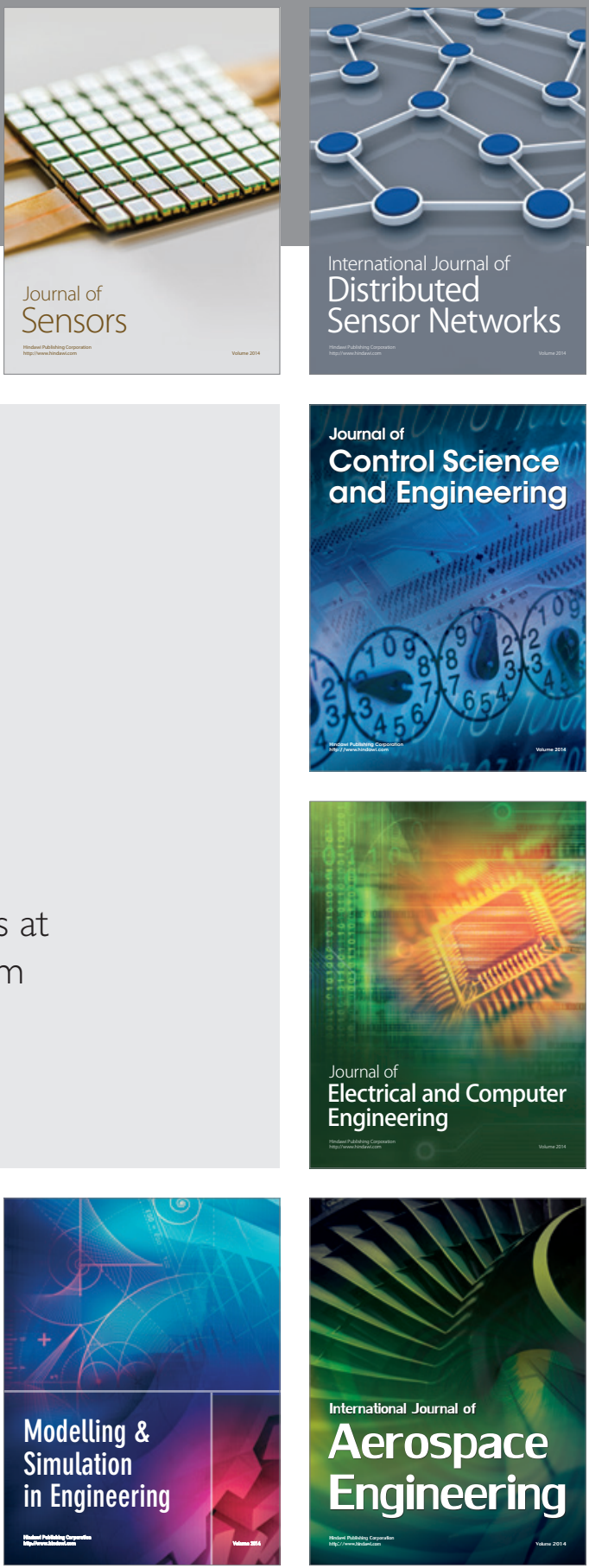

Journal of

Control Science

and Engineering
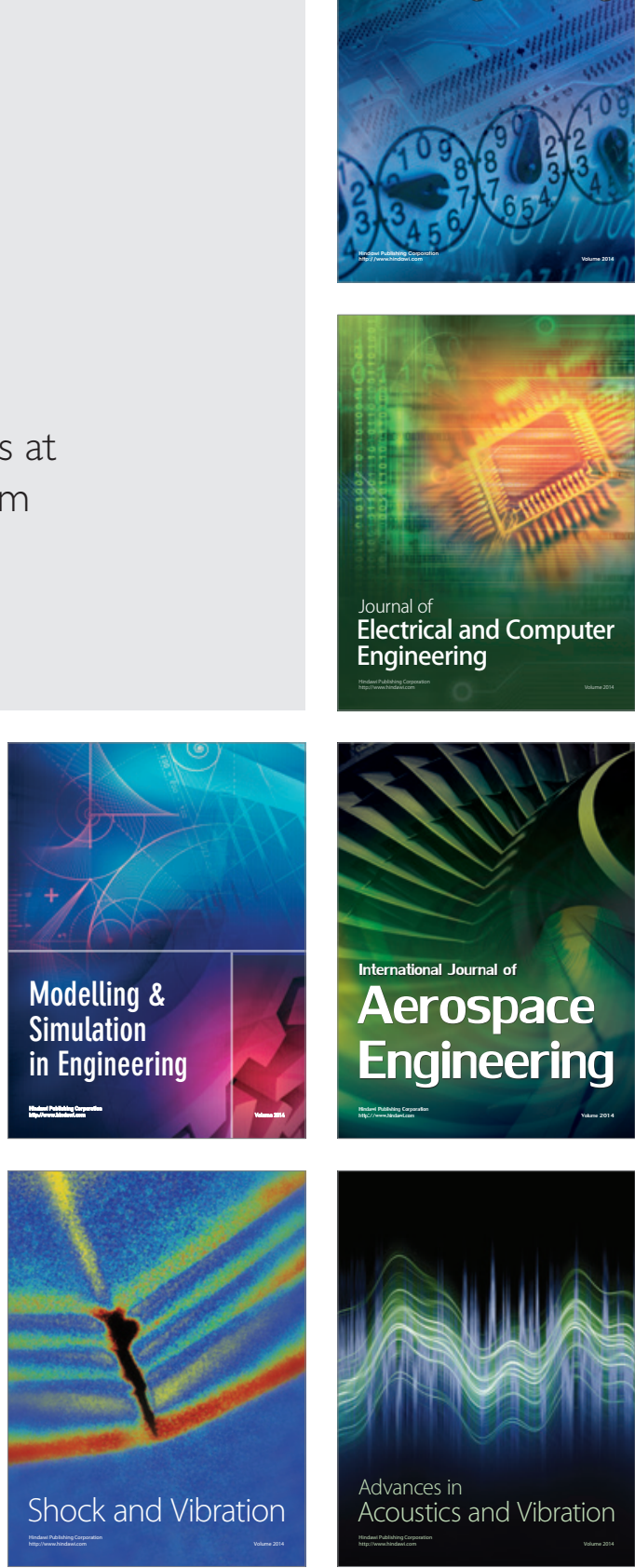